\section{Cistern sample}

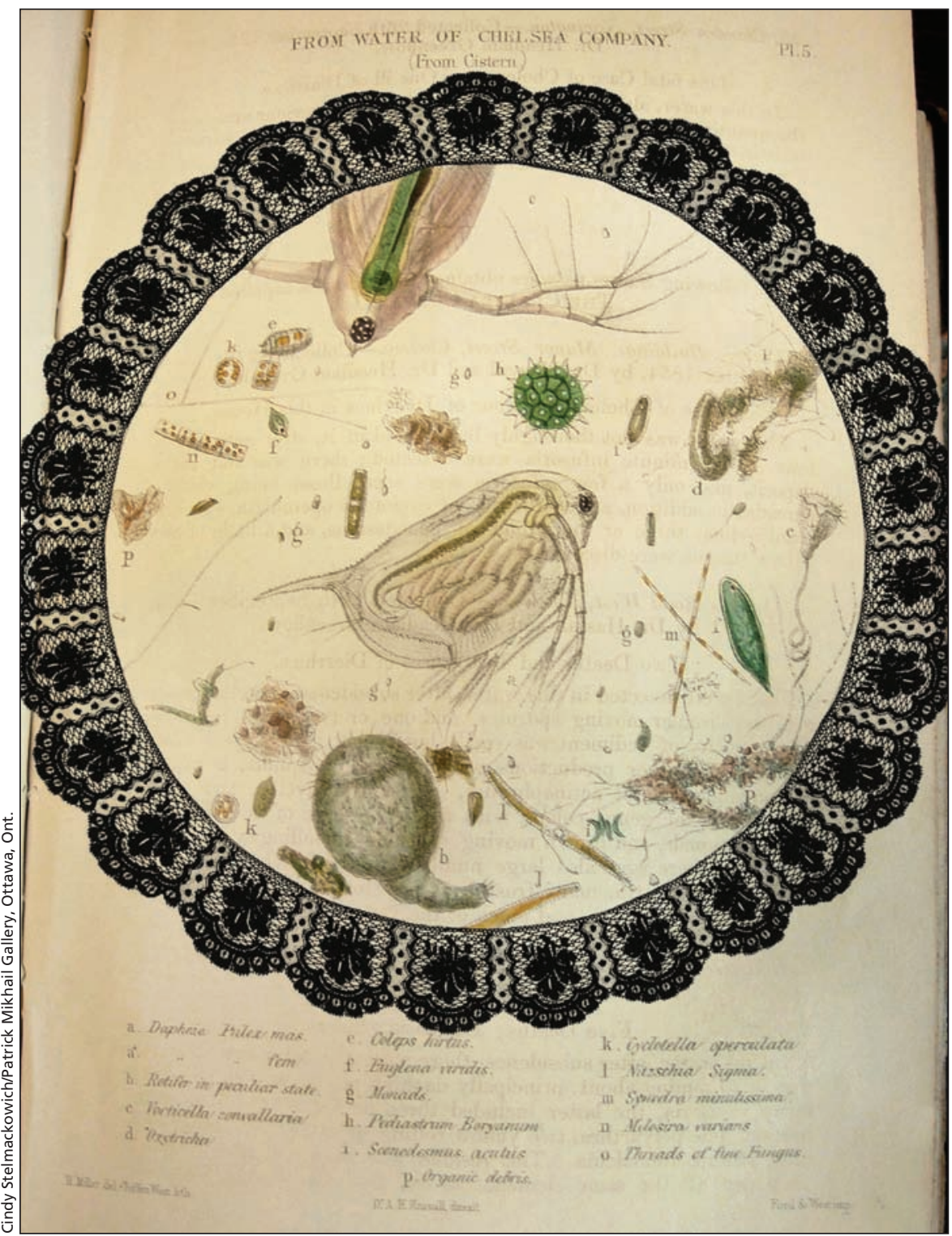

Cindy L. Stelmackowich, Cistern Sample, 1854: Cholera Shapes and Spaces Series (2009). Ultrachromium print. $61 \times 51 \mathrm{~cm}$. Cindy Stelmackowich's digital collages are based on re-reading 19th-century scientific imagery. After the cholera epidemic of 1854 in England, the London Board of Health published a series of reports based on microscopic examinations of the water and air. Since it was widely believed that disease traveled through the air and was the result of "filthy" conditions, both the air and the water were key areas of epidemic investigation. These reports by the Committee for Scientific Inquiries were some of the first government reports to use the new technology of the composite microscope. In focusing on the hand-drawn images produced in the effort to find a cure for epidemic disease, Stelmackowich has incorporated layers of 19th-century black mourning lace that she has collected over the past two years and digitally scanned. In this series entitled Cholera Shapes and Spaces, patterned black mourning lace appears as if to veil, cloak, and adorn this series of historical hand-drawn images. This digital series continues the artist's exploration of the visual obsessions of science and its strong attachments to decoration and esthetics.

\section{More Humanities} reading online

\section{Books}

How Doctors Think, by Jerome Groopman (Houghton Mifflin Co; 2008). This analysis of errors and mistakes pursues those routine medical cognitive processes that lead some doctors to get locked on to a particular diagnosis and treatment plan and stay with them when both are probably dubious, if not absolutely wrong. - J.T.H. Connor PhD, St. John's NL.

Take as Directed: Your Prescription for Safe Health Care in Canada, by Rhonda Church and Neil MacKinnon (ECW Press; 2010). The authors pose a fundamental question: How can a health care system that was designed 40-odd years ago continue to meet today's needs? Jane Doucet BJH, Halifax, NS

Pulse: Voices from the Heart of Medicine, Paul Gross, Diane Guernsey, editors (Change in Healthcare Publishing; 2010). This anthology of the first year of online offerings from Pulse Magazine's online format is, not surprisingly, is uneven. But more alarming is the unclear enforcement of the policy around patient confidentiality. - Ayelet Kuper MD DPhil, Toronto, Ont.

\section{Poetry}

An approach to the chest radiograph, Kedar Patil HBSc, London, Ont.; Love Poem, Shane Neilson MD, Guelph, Ont.

CMAJ 2011. DOI:10.1503/cmaj.110897

cmaj.ca 